\title{
La diversidad de artrópodos de España
}

\author{
José Luis Viejo Montesinos ${ }^{1}$
}

Sumario: I. INTRODUCCIÓN. II. LA DIVERSIDAD DE ARTRÓPODOS EN EL PLANETA. III. ¿CUÁNTAS ESPECIES DE ARTRÓPODOS EXISTEN EN ESPAÑA? IV. LA DIVERSIDAD DE ARTRÓPODOS ESPAÑOLES. 1. Crustáceos. 2. Arácnidos. 3. Miriápodos. 4. Insectos. V. ECOSISTEMAS O ÁREAS DE ESPECIAL INTERÉS PARA LOS ARTRÓPODOS. VI. BIBLIOGRAFÍA.

\section{INTRODUCCIÓN}

En el capítulo “La diversidad animal de España” hemos comentado el desigual reparto de las especies de organismos en los diferentes reinos e incluso troncos o phyla (véase la tabla 1 de dicho capítulo). Los artrópodos probablemente constituyen el $80 \%$ de todas las especies animales descritas hasta la fecha (tabla 2 del mismo capítulo); en números redondos podemos decir que del millón y medio de especies animales conocidas, un millón y cuarto son artrópodos y, de ellos, más de un millón son insectos, la tercera parte de los cuales son coleópteros. En este sentido cabe recordar la anécdota atribuida al eminente biólogo británico J.B.S. Haldane, quien a la pregunta de qué había aprendido acerca de Dios en su larga carrera científica respondió: "Su desmedida afición por los coleópteros”. En efecto, por número de especies, géneros, familias e incluso órdenes, los artrópodos son sin duda el tronco animal que más éxito ha tenido en la historia evolutiva.

Pero... ¿qué son los artrópodos? El tronco Arthropoda está formado por animales triblásticos (con tres capas embrionarias), celomados, bilateralmente simétricos, cuerpo segmentado, pero con segmentos agrupados en bloques (tagmas) diferentes, no como los anélidos, sistema nervioso central dorsal en el cerebro y ventral en la cadena nerviosa, corazón dorsal, circulación abierta y, como rasgo claramente distintivo, con un exoesqueleto más o menos endurecido constituido principalmente por proteínas y quitina, que ha de eliminarse de vez en cuando para que el animal pueda crecer, es decir, que realizan mudas.

1 Catedrático. Departamento de Biología. Universidad Autónoma de Madrid. 
Los artrópodos son un grupo evolutivamente antiguo, ya que se encuentran fósiles desde la base del Cámbrico, e incluso se especula que antes; es decir, están en el Planeta desde hace al menos 550 millones de años. La historia de la vida en la Tierra no se entendería sin los artrópodos; su inmensa diversidad, biomasa, diversidad ecológica y evolutiva hacen de este tronco uno de los pilares clave para entender el funcionamiento de los ecosistemas. Son tan ubicuos, que podemos encontrar artrópodos desde las más profundas simas oceánicas, hasta las altas capas de la troposfera, o las selvas tropicales y los desiertos; son comunes en el suelo o como parásitos en el interior de otros animales o de plantas; forman agallas, son capaces de resistir la desecación total, la congelación prolongada y la anoxia.

Los artrópodos, y en particular los insectos, causan a los seres humanos numerosas molestias, problemas y enfermedades, bien por acción directa: molestias, daño accidental a órganos, envenenamiento, dermatosis, miasis, fobias, etc.; bien por acción indirecta: transmisores pasivos de patógenos, vectores obligados de patógenos, etc. Los insectos son los agentes transmisores de algunas de las enfermedades más dañinas para la Humanidad, como la malaria, las tripanosomiasis, la fiebre amarilla, el dengue o la peste. Igualmente, estos organismos afectan a la agricultura y a la ganadería, sectores que sin duda se ven perjudicados, aunque es preciso matizar que en lo que concierne a la agricultura, los beneficios proporcionados por los insectos superan con creces los perjuicios ocasionados. Así, se estima que las plagas de artrópodos (sobre todo insectos) causan alrededor de 400 millones de euros al año de pérdidas a la agricultura mundial, aunque, también según algunas estimaciones, los beneficios por polinización de cultivos alcanzan los 17.000 millones de euros al año, ya que alrededor de 90 cultivos diferentes son polinizados por insectos.

Los insectos son organismos clave para el desarrollo de las ciencias (y no sólo biológicas), ya que tienen o han tenido una capital importancia en la Ecología, Biogeografía, Evolución, Genética, Fisiología, Medicina, e incluso en la Física y la Química. Al ser las poblaciones de insectos tan ubicuas y numerosas, intervienen en numerosos procesos de los ecosistemas terrestres y dulceacuícolas, como polinización, depredación, parasitismo, control de poblaciones, etc. Contribuyen eficazmente a la formación del suelo, a los ciclos de nutrientes y al tratamiento de residuos. El mundo sin los insectos no se parecería nada a lo que conocemos. Para empezar las flores, tal y como son actualmente, no existirían, dado que en la mayor parte de los casos, estas estructuras reproductoras han sido evolutivamente modeladas por los insectos, a lo largo de cientos de millones de años de evolución conjunta. Así, los colores, formas y olores de la mayoría de las flores responden a unas claves evolutivas relacionadas con la atracción de los insectos que han de transportar el polen de las anteras de una flor al carpelo de otra. También podemos aducir razones estrictamente económicas para proteger los insectos. A los beneficios económicos como polinizadores que acabamos de mencionar, se unen los derivados del control biológico que ejercen sobre otras plagas, sean de insectos, sean de plantas invasoras: malas hierbas, matorral invasor, etc. Los insectos son productores de miel, cera y otros productos apícolas, además de recolec-

114 tores de polen como alimento humano. Pero es que como alimento humano en sí, los 
insectos también constituyen un recurso de primera magnitud. Se trata de los insectos comestibles que no porque en Europa no formen parte de la dieta humana, dejan de serlo en muchos otros lugares del planeta, como China, México, Centroamérica, Colombia, numerosos países africanos, etc. $Y$ es probable que en el futuro se conviertan en una fuente de alimento de creciente demanda, dadas sus buenas cualidades nutricias. Las barreras principales que frenan el consumo de insectos son de tipo cultural, comparables a las que algunos grupos humanos establecen frente a los crustáceos, por otra parte tan apreciados en España y otros países con tradición pesquera. Además, se estima que a lo largo de la vida, una persona de una cultura no insectívora se come inadvertidamente más de un kilo de insectos, en forma de larvas, pupas o adultos de Tenebrio molitor (el escarabajo de la harina), o de Sitophilus zeamais (el gorgojo del maíz), Ostrinia nubialis (un lepidóptero taladrador del maíz), u otros insectos propios de productos almacenados que se trituran con el grano, por no hablar de los pulgones que vienen con las ensaladas, o los lepidópteros que se procesan a la vez que la fruta para compotas, mermeladas u otras conservas vegetales.

\section{LA DIVERSIDAD DE ARTRÓPODOS EN EL PLANETA}

Los artrópodos son un tronco morfológicamente homogéneo en términos generales. Se divide en cuatro grandes categorías: Crustáceos, Quelicerados, Miriápodos y Hexápodos (normalmente conocidos como Insectos). La diversidad de especies es muy desigual según el grupo. En la tabla 1 mostramos el número aproximado de especies conocidas de cada uno de los troncos, con indicación de la residencia ecológica más común en el grupo. Consúltese también la tabla 3 del capítulo "La diversidad animal de España". En la tabla 2 recogemos una estimación de la diversidad de especies de artrópodos.

\section{Abreviaturas}

$\mathrm{M}=$ marino.

$\mathrm{D}=$ dulceacuícola.

$\mathrm{T}=$ terrestre.

$\mathrm{P} \quad$ = parásito.

M = grupo exclusivamente marino.

Md = mayoritariamente marino, con algunas especies en las aguas dulces.

Mdt = mayoritariamente marino, con algunas especies en las aguas dulces y en el medio terrestre.

MDT = se encuentran bien representados en todos los medios marino, dulceacuícola y terrestre.

$\mathrm{mD}=$ mayoritariamente dulceacuícolas, pero también marinos.

mdT = mayoritariamente terrestres, con algunas especies acuáticas.

$\mathrm{T}=$ exclusivamente terrestres.

DT = exclusivamente terrestres $\mathrm{y}$ de agua dulce.

$\mathrm{P} \quad=$ exclusivamente parásitos+. 
TABLA 1*

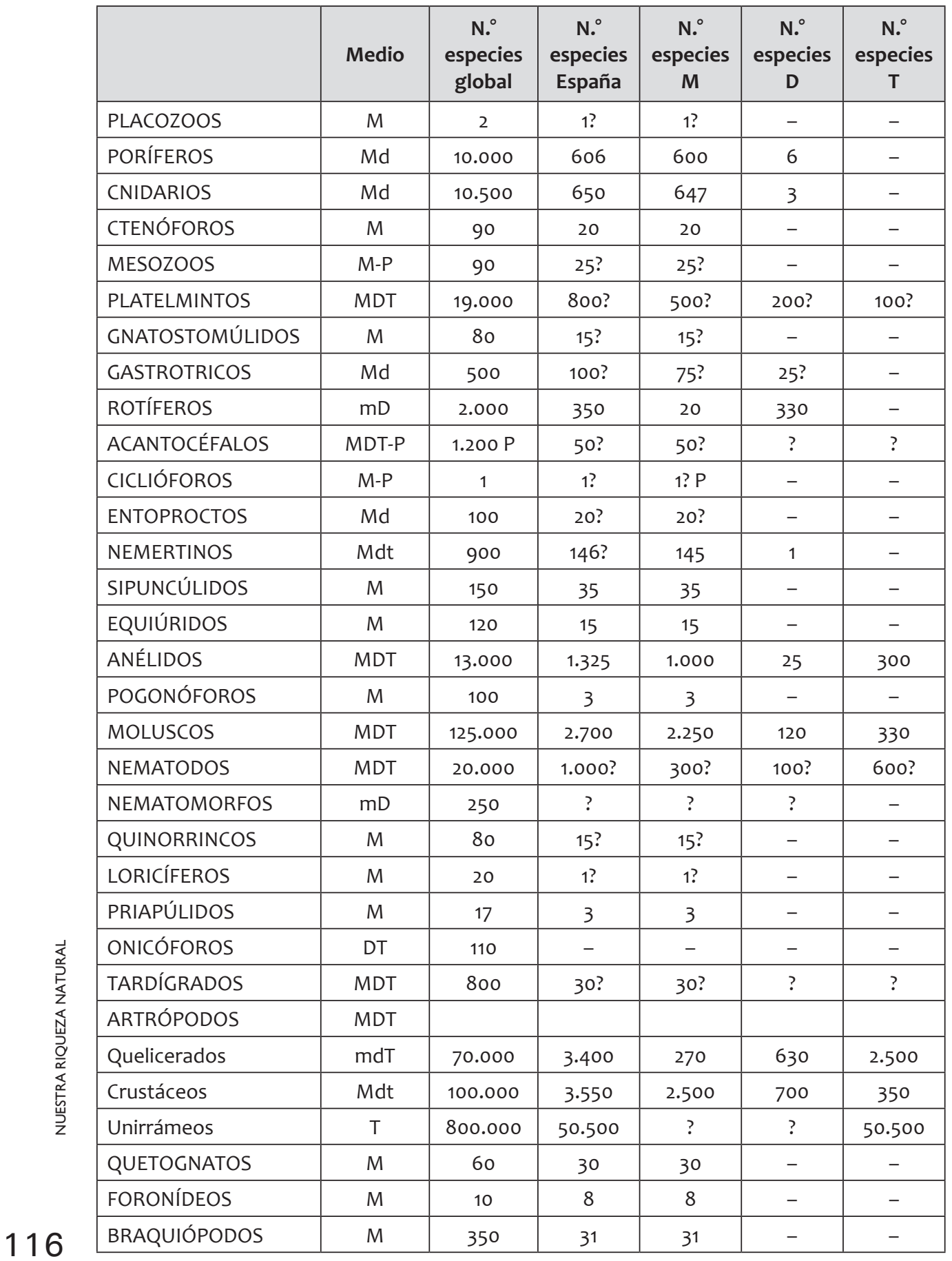


TABLA 1* (cont.)

\begin{tabular}{|l|c|c|c|c|c|c|}
\hline & Medio & $\begin{array}{c}\mathbf{N}^{\circ} \\
\text { especies } \\
\text { global }\end{array}$ & $\begin{array}{c}\mathbf{N}^{\circ} \\
\text { especies } \\
\text { España }\end{array}$ & $\begin{array}{c}\mathbf{N}^{\circ} \\
\text { especies } \\
\mathbf{M}\end{array}$ & $\begin{array}{c}\mathbf{N}^{\circ} \\
\text { especies } \\
\mathbf{D}\end{array}$ & $\begin{array}{c}\mathbf{N}^{\circ} \\
\text { especies } \\
\mathbf{T}\end{array}$ \\
\hline BRIOZOOS & Md & 4.500 & 300 & 300 & $?$ & - \\
\hline EQUINODERMOS & $\mathrm{M}$ & 7.000 & 300 & 300 & - & - \\
\hline HEMICORDADOS & $\mathrm{M}$ & 80 & 5 & 5 & - & - \\
\hline CORDADOS & MDT & & & & & \\
\hline Urocordados & $\mathrm{M}$ & 1.400 & 350 & 350 & - & - \\
\hline Cefalocordados & $\mathrm{M}$ & 25 & 2 & 2 & - & - \\
\hline Vertebrados & MDT & 51.000 & 1.792 & 1.180 & 108 & 504 \\
\hline TOTAL & & 1.238 .535 & 68.179 & 10.747 & 2.248 & 55.184 \\
\hline
\end{tabular}

* Relación de los Phyla animales actuales con indicación de su presencia relativa en los medios marino, dulceacuícola o terrestre (primera columna), número de especies a nivel mundial (segunda), número de especies en España (tercera), y número de especies presentes en cada uno de los tres grandes medios (cuarta = medio marino, quinta = dulceacuícola, y sexta = terrestre). Una interrogación después de una cifra significa que el grupo está insuficientemente estudiado y el número de especies es estimativo. Una interrogación aislada significa que no se dispone de datos que permitan hacer una estimación.

Fuente: Extraído de Ramos y Templado, 2002.

TABLA 2

Estimación del número de especies descritas de cada uno de los cuatro grandes grupos de artrópodos

\begin{tabular}{|l|c|c|}
\hline & Mundo & España \\
\hline CRUSTÁCEOS & 70.000 & 3.400 \\
\hline QUELICERADOS & 100.000 & 3.550 \\
\hline MIRIÁPODOS & 12.000 & 300 \\
\hline INSECTOS & 800.000 & 50.500 \\
\hline TOTAL & 982.000 & 57.750 \\
\hline
\end{tabular}

Fuente: Elaboración propia a partir de diversas fuentes.

Si volvemos a las tablas 1 y 2 veremos que los crustáceos son el grupo con menos especies descritas (y aún así se conocen unas 70.000) de los “tres grandes”, mientras que los insectos son el más diverso; sin embargo, lo que no dicen las cifras es que la morfología de los insectos es la más homogénea, mientras que la de los crustáceos es la más dispar; dicho en pocas palabras y con evidente hipérbole: visto un insecto, vistos todos; visto un crustáceo no nos podremos hacer una idea de cómo son los demás. Los quelicerados son también un grupo morfológicamente homogéneo, en el que la mayoría de las especies se incluyen en la clase de los arácnidos, de los que los 
más conocidos son las arañas (Araneae), pero a los que pertenecen también los ácaros (Acari), que superan a las arañas en número de especies conocidas, pero aún así son un grupo taxonómicamente poco conocido y del que se describen especies nuevas constantemente (tabla 2 de este capítulo). Comparados con los demás grupos de artrópodos, los miriápodos son un grupo menor, ya que se conocen unas 12000 especies; se trata de artrópodos con numerosos pares de patas (de 10 a 375), con tamaños muy variables: desde $0,5 \mathrm{~mm}$ a $25 \mathrm{~cm}$ de longitud; en los miriápodos se reconocen cuatro clases: Diplópodos, quilópodos, paurópodos y sínfilos; la que más especies tiene es la clase de los diplópodos, con unas 7500 especies conocidas en el mundo.

\section{III. ¿CUÁNTAS ESPECIES DE ARTRÓPODOS EXISTEN EN ESPAÑA?}

Como sucede con otros grupos de invertebrados, las cifras de diversidad de artrópodos son altamente especulativas. Al igual que en otros casos es preciso distinguir entre las especies cuya existencia es conocida para los taxónomos (especies descritas) y las especies aún por describir. A menos que digamos lo contrario, normalmente nos referiremos a las primeras, es decir las especies que "ya tienen nombre", si bien en muchos casos poco más se sabe de ellas.

Para un análisis más detallado, en las siguientes tablas expondremos las estimaciones acerca del número de especies de cada uno de los grandes grupos de artrópodos en España. En la tabla 3 mostramos las estimaciones sobre la diversidad de crustáceos en España.

Estas estimaciones tienen un alto grado de incertidumbre, como se puede colegir de las comparaciones con la fauna mundial y con la referencia italiana; así consideramos que el número de especies de ostrácodos que debe haber en España podría ser cinco veces superior, y algo parecido le debe pasar a los isópodos. Llama la atención la escasa representación de los concostráceos, y la ausencia de datos de grupos como cirrípedos y branquiuros, entre otros; por el contrario, el número de especies de decápodos probablemente se acerque la cifra real, tanto de especies ya descritas, como de especies aún por describir.

En la tabla 4 indicamos el número aproximado de especies de quelicerados presentes en la península Ibérica, comparado con las especies citadas (conocidas) en el mundo y en Italia, a partir de datos recopilados por Ortuño (2002).

De los datos expuestos podemos comentar que es probable que el número de especies descritas de arañas (Araneae) y de ácaros (Acari) sea considerablemente menor que los que realmente existen, y que a este grado de incertidumbre se añade el escaso conocimiento de la fauna española, en particular la de ácaros, que si bien está razonablemente bien conocida en el caso de los oribátidos, lo es bastante menos en

118 otros grupos. 
$\operatorname{TABLA} 3$ (cont.)

Estimación del número de especies de crustáceos presentes en la península lbérica, comparado con el número de especies mundiales e italianas conocidas

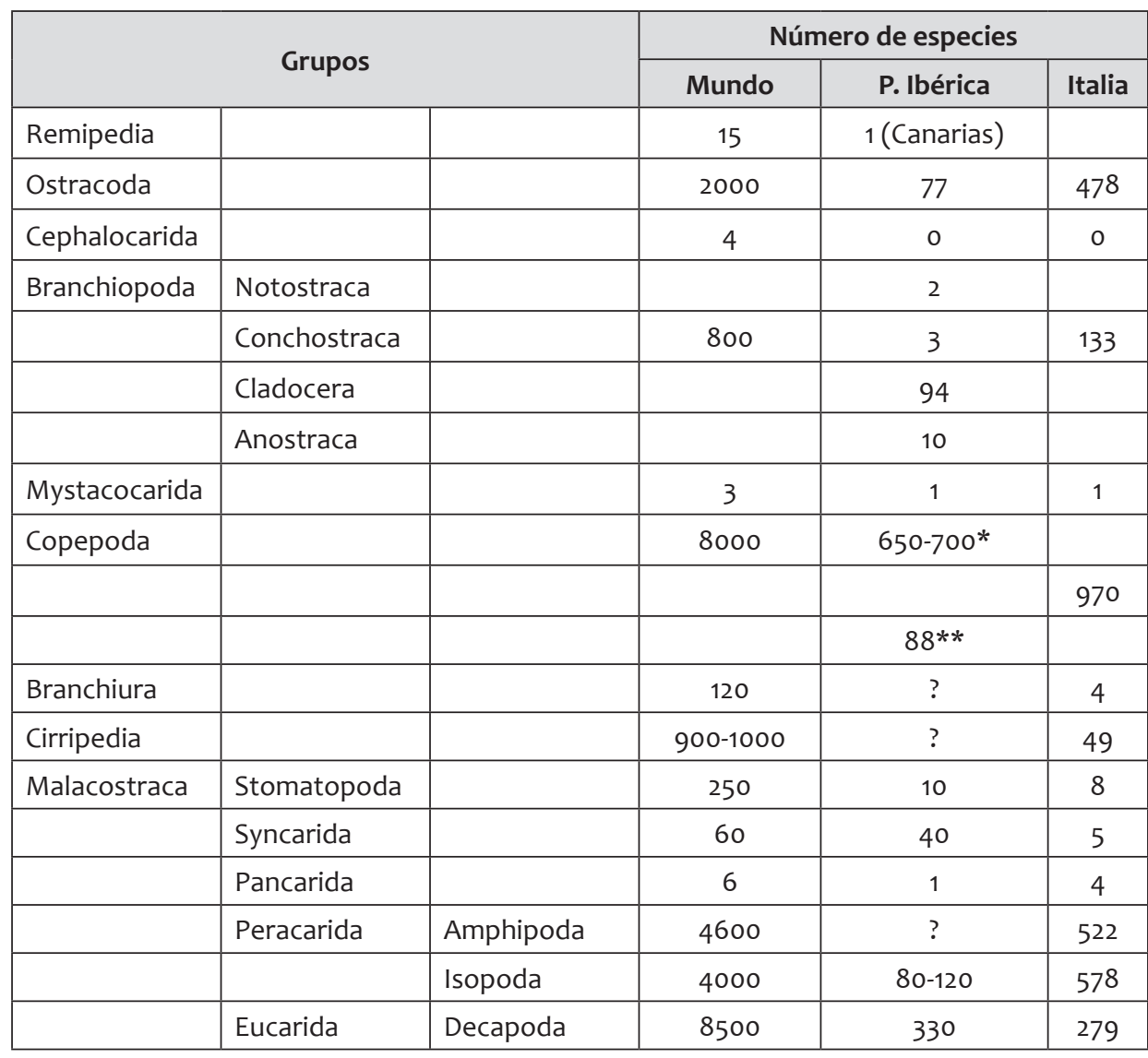

* Especies marinas.

** Especies dulceacuícolas.

Fuente: Modificado de Ortuño, 2002

TABLA 4

Número de especies de quelicerados presentes en la península Ibérica, comparado con el número de especies mundiales e italianas conocidas

\begin{tabular}{|l|l|c|c|c|}
\hline \multicolumn{2}{|c|}{ Grupos } & \multicolumn{3}{c|}{ Número de especies } \\
\cline { 3 - 5 } & & Mundo & P. Ibérica & Italia \\
\hline Merostomata & & 5 & 0 & 0 \\
\hline Arachnida & Scorpionida & 600 & 4 & 4 \\
\hline & Solifugae & $600 ?$ & 1 & 2 \\
\hline
\end{tabular}




\section{TABLA 4 (cont.)}

Número de especies de quelicerados presentes en la península lbérica, comparado con el número de especies mundiales e italianas conocidas

\begin{tabular}{|l|l|c|c|c|}
\hline \multirow{2}{*}{} & \multirow{2}{*}{ Grupos } & \multicolumn{3}{c|}{ Número de especies } \\
\cline { 3 - 5 } & Pseudoscorpionida & Mundo & P. Ibérica & Italia \\
\hline & Ricinuleida & 3000 & 135 & 209 \\
\hline & Palpigradi & $16-20$ & 0 & 0 \\
\hline & Uropygi & 35 & 304 & 9 \\
\hline & Amblypygi & 5 & 0 & 0 \\
\hline & Schizomida & 60 & 0 & 0 \\
\hline & Araneae & 30 & 1 (Canarias) & 0 \\
\hline & Opiliones & $220000-26000$ & $1.100-1.200$ & 1.361 \\
\hline & Acari & 30.000 & 115 & 120 \\
\hline & & $6.000-7.000^{*}$ & $312^{* *}$ & 2868 \\
\hline Pycnogonida & & $>600$ & $54-55$ & 44 \\
\hline
\end{tabular}

* Oribatida.

** Actinedida dulceacuícolas.

Fuente: Tomado de Ortuño, 2002

En la tabla 5 mostramos el número de especies conocidas de las cuatro clases de miriápodos. Los diplópodos (conocidos como milpiés) son el grupo más diverso, con unas 10000 especies conocidas, la mayor parte en áreas tropicales; en esta clase se reconocen 14 órdenes. Los quilópodos (ciempiés) tienen unas 2500 especies, 96 de las cuales al menos están presentes en la península Ibérica, cuya representación faunística es considerablemente mayor que la de la clase anterior.

\section{TABLA 5}

Número de especies de miriápodos presentes en la península Ibérica, comparado con el número de especies mundiales

\begin{tabular}{|l|c|c|}
\hline \multirow{2}{*}{} & \multicolumn{2}{|c|}{ Número de especies } \\
\cline { 2 - 3 } & Mundo & P. Ibérica \\
\hline Diplopoda & 10000 & 90 \\
\hline Chilopoda & 2500 & 96 \\
\hline Pauropoda & 500 & 49 \\
\hline Symphyla & 160 & 22 \\
\hline Total & 13160 & 257 \\
\hline
\end{tabular}

Fuente: Elaboración propia a partir de diversas fuentes, principalmente Parker (1982) 
Ya hemos indicado que los insectos constituyen el grupo animal más diverso, ya que, aunque las cifras oscilen bastante, una estimación conservadora establece que existen al menos 800.000 especies descritas, y algunas otras aproximan el número total de especies (conocidas o no) a la asombrosa cifra de cien millones (véase tabla 1 del capítulo "La diversidad animal en España”). A pesar de esta inmensa diversidad específica, los insectos muestran una sorprendente uniformidad morfológica, desde luego superior a la de otros artrópodos como los crustáceos o los quelicerados. Para que el lector no se pierda con la ingente cantidad de nombres y de cifras, a continuación exponemos una lista ordenada de los 31 órdenes que se suelen reconocer en este gran grupo de artrópodos, no todos los cuales están presentes en España (en la tabla se indican como ausente). En primer lugar aclararemos la cuestión del nombre, ya que si bien el nombre de insectos es el más conocido entre el público no experto, desde un punto de vista técnico, estos artrópodos han de denominarse hexápodos, reservándose el nombre de insectos para unos cuantos órdenes (realmente la mayoría), la mayor parte de los cuales son primariamente alados.

\section{SUPERCLASE HEXAPODA}

- CLASE DIPLURA
1. Diplura

- CLASE PROTURA
2. Protura

- CLASE COLLEMBOLA

\section{Collembola}

- CLASE INSECTA

- Subclase Apterigota

4. Archaeognatha

5. Zygentoma

- Subclase Pterygota

6. Ephemeroptera

7. Odonata

8. Plecoptera

9. Embioptera

10. Phasmida

11. Mantophasmatodea Ausente

12. Orthoptera

13. Grylloblattaria Ausente

14. Dermaptera

15. Dictyoptera

16. Zoraptera

Ausente

17. Psocoptera

18. Phtiriaptera

19. Hemiptera 

20. Thysanoptera
21. Strepsiptera
22. Coleoptera
23. Raphidioptera
24. Megaloptera
25. Neuroptera
26. Hymenoptera
27. Trichoptera
28. Lepidoptera
29. Mecoptera
30. Siphonaptera
31. Diptera

En la tabla 6 mostramos una aproximación a la diversidad de especies de insectos (Hexapoda) a partir de los datos que ofrece ORTUÑO (2002). En esta tabla los datos referidos a Colémbolos, Dipluros, Homópteros, Coleópteros y Estrepsípteros son meras estimaciones, elaboradas por comparación con los países vecinos, y que no aparecen en la fuente original. Los datos de los dípteros (salvo el número de especies de Francia) proceden de CARLES-TOLRÁ (2002). Con respecto a la lista de 31 órdenes, hay que advertir varios cambios: no se incluyen los Mantophasmatodea, los Dyctioptera están desglosados en Mantodea y Blattodea, y los Microcoryphia son los Archaeognatha, entre otras pequeñas disparidades.

\section{TABLA 6}

Número de especies de insectos (sensu lato) descritas en el mundo y que se estima están presentes en la península Ibérica, Francia, Italia y Gran Bretaña

\begin{tabular}{|c|c|c|c|c|c|c|}
\hline & \multirow{2}{*}{ Órdenes } & \multicolumn{5}{|c|}{ Número de especies } \\
\hline \multirow{10}{*}{ 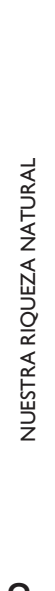 } & & Mundo & P. Ibérica & Francia & Italia & Gran Bretaña \\
\hline & Collembola & 6500 & 500 & 500 & 418 & 304 \\
\hline & Protura & 500 & 13 & 10 a 20 & 31 & 12 \\
\hline & Diplura & 800 & 50 & $45-60$ & 73 & 12 \\
\hline & Microcoryphia & 300 & 61 & 38 & 48 & 7 \\
\hline & Thysanura (Zygentoma) & 500 & 41 & 10 a 13 & 19 & 2 \\
\hline & Ephemeroptera & 2000 & 121 & 140 & 94 & 46 \\
\hline & Odonata & 6000 & 78 & 87 & 88 & 45 \\
\hline & Plecoptera & 1900 & 136 & 150 & 144 & 34 \\
\hline & Blattodea & 4000 & 20 & 18 & 40 & 8 \\
\hline
\end{tabular}


TABLA 6 (cont.)

Número de especies de insectos (sensu lato) descritas en el mundo y que se estima están presentes en la península Ibérica, Francia, Italia y Gran Bretaña

\begin{tabular}{|c|c|c|c|c|c|}
\hline \multirow{2}{*}{ Órdenes } & \multicolumn{5}{|c|}{ Número de especies } \\
\hline & Mundo & P. Ibérica & Francia & Italia & Gran Bretaña \\
\hline Isoptera & 2200 & 2 & 3 & 2 & 0 \\
\hline Mantodea & 1900 & 14 & 9 & 12 & 0 \\
\hline Grylloblattodea & 25 & 0 & 0 & 0 & 0 \\
\hline Dermaptera & 1840 & 20 & 20 & 22 & 7 \\
\hline Orthoptera & 19000 & 307 & 212 & 333 & 30 \\
\hline Phasmatodea & 2500 & 4 & 3 & 8 & 0 \\
\hline Embioptera & 275 & 4 & 3 & 5 & 0 \\
\hline Zoraptera & 30 & 0 & 0 & 0 & 0 \\
\hline Psocoptera & 3000 & 115 & 108 & 102 & 87 \\
\hline Anoplura & 490 & 29 & 30 & 267 & 539 \\
\hline Mallophaga & 3000 & 273 & 150 & & \\
\hline Homoptera & 49500 & 2000 & 2050 & 2147 & 1150 \\
\hline Heteroptera & 32600 & 1400 & 1500 & 1380 & 516 \\
\hline Tysanoptera & 5600 & 249 & 346 & 213 & 167 \\
\hline $\begin{array}{l}\text { Neuroptera (sensu lato) } \\
\text { Megaloptera }\end{array}$ & 270 & 4 & 3 & 4 & 2 \\
\hline Raphidioptera & 175 & 12 & 17 & 20 & 4 \\
\hline Neuroptera (sensu stricto) & 5000 & 152 & 160 & 153 & 54 \\
\hline Mecoptera & 500 & 4 & 9 & 10 & 4 \\
\hline Coleoptera & 330000 & 10000 & 9600 & 11989 & 3700 \\
\hline Strepsiptera & 532 & 15 & 10 a 15 & 21 & 10 \\
\hline Siphonaptera & 1900 & 86 & 90 & 81 & 61 \\
\hline Diptera & 132111 & 6106 & 6500 & 6552 & 6668 \\
\hline Trichoptera & 7000 & 316 & 244 & 367 & 192 \\
\hline Lepidoptera & 165000 & 4243 & 5120 & 5083 & 2400 \\
\hline Hymenoptera & 115000 & 9400 & 8000 & 7526 & 6641 \\
\hline TOTAL & 893837 & 35775 & 35110 & 37315 & 22034 \\
\hline
\end{tabular}

Fuente: Modificado a partir de Ortuño (2002). 
Como se puede ver, en la península Ibérica los coleópteros e himenópteros son los dos órdenes con mayor número de especies, alrededor de diez mil cada uno; llama la atención la alta proporción de himenópteros ibéricos con respecto al total (más de un $8 \%$ ), cuando la media apenas llega al 5\%; este fenómeno es general en los países templados, ya que los himenópteros no siguen tan de cerca la norma del gradiente latitudinal en relación con la diversidad.

En la tabla 7 mostramos unas cifras de biodiversidad canaria que nos dan una idea tanto del número de especies, como (y esto es particularmente relevante) del número de endemismos, es decir, especies que sólo se hallan en el archipiélago. Como se puede advertir, los artrópodos terrestres endémicos constituyen más del $40 \%$ de la fauna, lo que confiere a la fauna canaria una singularidad extraordinaria.

\section{TABLA 7}

Número aproximado de especies de artrópodos de Canarias, en comparación con otros grupos

\begin{tabular}{|l|c|c|c|c|c|}
\hline \multicolumn{1}{|c|}{ Grupo } & Terrestres & Endemismos & Marinos & Endemismos & Total \\
\hline Artrópodos & 6.378 & 2.835 & 720 & 1 & 7.098 \\
\hline Otros invertebrados & 774 & 223 & 3.563 & 9 & 4.337 \\
\hline Vertebrados & 365 & 21 & 770 & 2 & 1.135 \\
\hline Plantas & 2.489 & 528 & 3 & & 2.492 \\
\hline
\end{tabular}

Fuente: Modificado de Machado, 2002.

\section{LA DIVERSIDAD DE ARTRÓPODOS ESPAÑOLES}

A continuación daremos un somero repaso a la diversidad de algunos de los grupos de artrópodos más relevantes. Por otra parte, y debido a la creciente preocupación por la conservación de la fauna, en España se han ido incorporando diversas especies al Catálogo Nacional de Especies Amenazadas, lo que recogemos en la tabla 8 (MMARM, 2009); véase también la tabla 4 del capítulo "La diversidad animal en España".

\section{Crustáceos}

Como hemos señalado antes (tabla 2), se puede estimar que en España puede haber unas 3500 especies de entre todas las descritas en el planeta. El grupo más diverso probablemente sea el de los copépodos, pequeños crustáceos del plancton, de capital importancia en las redes tróficas marinas. El segundo gran grupo por número de especies es el de los decápodos, que se parecen más a lo que una perso-

124 na no experta entiende que es un crustáceo; estas criaturas tienen un tamaño rela- 
tivamente grande, en comparación con el resto de crustáceos, y aún de otros artrópodos, ya que entre ellos están los artrópodos de mayor tamaño en el mundo, como Macrocheira kaempferi o cangrejo gigante del Japón, o los de mayor tamaño en España, como seguramente sea el bogavante, Homarus gammarus o el centollo, Maia squinado.

\section{TABLA 8}

Lista de especies de artrópodos incluidas en el Catálogo Nacional de Especies Amenazadas

\begin{tabular}{|c|c|}
\hline Especie & Categoría \\
\hline Acrostira euphorbiae (García y Oromi, 1992) & En Peligro de Extinción \\
\hline Halophiloscia canariensis (Dalens, 1973) & En Peligro de Extinción \\
\hline Maiorerus randoi (Rambla,1991) & En Peligro de Extinción \\
\hline Pimelia granulicollis(Wollaston, 1864) & En Peligro de Extinción \\
\hline Rhopalomesites eophorbiae (Wollaston,1864) & En Peligro de Extinción \\
\hline Panulirus echinatus Smith, 1869 & En Peligro de Extinción \\
\hline Munidopsis polimorpha (Koelbe) & En Peligro de Extinción \\
\hline Speleonectes ondinae (García-Valdecasas, 1984) & En Peligro de Extinción \\
\hline Ophiogomphus cecilia (Fourcroy, 1785) & En Peligro de Extinción \\
\hline Polyommatus golgus (Hübner, 1808) & En Peligro de Extinción \\
\hline Macromia splendens (Pictet, 1843) & En Peligro de Extinción \\
\hline Lindenia tetraphylla (Van der Linden, 1825) & En Peligro de Extinción \\
\hline Osmoderma eremita Scopoli, 1763 & Sensible a la alteración de su hábitat \\
\hline Cucujus cinnaberinus (Scopoli, 1774) & Sensible a la alteración de su hábitat \\
\hline Limoniscus violaceus (Müller, 1821) & Sensible a la alteración de su hábitat \\
\hline Oxygastra curtisii (Dale, 1834) & Sensible a la alteración de su hábitat \\
\hline Baetica ustulata Rambur, 1838 & Sensible a la alteración de su hábitat \\
\hline Candelacypris aragonica (Brehm Margalef, 1948) & Sensible a la alteración de su hábitat \\
\hline Buprestis splendens (Fabricius, 1775) & Vulnerable \\
\hline Maculinea nausithous (Bergsträsser, 1779) & Vulnerable \\
\hline Chasmatopterus zonatus Escalera, 1925 & Vulnerable \\
\hline Carabus (Mesocarabus) riffensis Fairmaire, 1872 & Vulnerable \\
\hline Austropotamobius pallipes Lereboullet, 1858 & Vulnerable \\
\hline Lucanus cervus (Linnaeus, 1767) & De Interés Especial \\
\hline Rosalia alpina (Linnaeus, 1758) & De Interés Especial \\
\hline Apteromantis aptera (Fuente, 1894) & De Interés Especial \\
\hline
\end{tabular}


TABLA 8 (cont.)

Lista de especies de artrópodos incluidas en el Catálogo Nacional de Especies

Amenazadas

\begin{tabular}{|l|l|}
\hline \multicolumn{1}{|c|}{ Especie } & \multicolumn{1}{c|}{ Categoría } \\
\hline Gomphus graslinii Rambur, 1842 & De Interés Especial \\
\hline Coenonympha oedippus (Fabricius, 1787) & De Interés Especial \\
\hline Eriogaster catax (Linnaeus, 1758) & De Interés Especial \\
\hline Graellsia isabelae (Graells, 1849) & De Interés Especial \\
\hline Coenagrion mercuriale (Charpentier, 1840) & De Interés Especial \\
\hline Dorysthenes (Opisognathus) forficatus (Fabricius, 1792) & De Interés Especial \\
\hline
\end{tabular}

Fuente: MMARM, 2009.

En el Catálogo Nacional de Especies Amenazadas se han incluido las especies Panulirus echinatus, Munidopsis polimorpha y Speleonectes ondinae en la categoría de En peligro de extinción. La primera es la langosta herreña, cuya distribución en España se limita a la isla del Hierro, con contadas referencias a la de Tenerife. Munidopsis polimorpha recibe el nombre popular de "jameíto" y es un decápodo galateido exclusivo del lago de los Jameos del Agua (Lanzarote). Speleonectes ondinae es otro habitante exclusivo de los Jameos del Agua; se trata de un raro crustáceo translúcido y alargado de la subclase Remipedia (TEMPLADO et al., 2004). En la categoría de Sensible a la alteración de su hábitat se encuentra el ostrácodo Candelacypris aragonica, propio de las lagunas endorreicas de Los Monegros (Zaragoza).

Otros crustáceos que podemos destacar por su rareza o singularidad son los siguientes:

- Austropotamobius pallipes, o cangrejo de río autóctono. Se trata de un decápodo ligado a los cursos de agua de la España caliza, seriamente amenazado por la alteración de los ríos y, sobre todo, por una epizootia llamada afanomicosis que ha acabado con la mayor parte de las poblaciones ibéricas desde los años ochenta. Para más información consúltese la ficha de BOLEA (2001).

- Typhlatya miravetensis, una pequeña gamba (Decapoda, Atyidae) exclusiva de una cavidad lagunar en el Ullal de la Rambla de Miravet, Cabanes (Castellón), considerada "en peligro crítico" en el Libro Rojo de los Invertebrados de Espa$\tilde{n} a$ (Verdú y Galante, 2006).

\section{Arácnidos}

Los arácnidos con mayor número de especies en España seguramente sean los

126 ácaros, de los que sólo el grupo de los oribátidos tiene más de mil especies. La fauna 
de arañas de España no está aún bien conocida, y se estima que debe albergar más de 1500 especies, de las que hasta ahora se han citado alrededor de 1200, agrupadas en 48 familias (ORTUÑO, 2002). Entre las especies que podemos destacar está Macrothele calpeiana, conocida como araña negra de los alcornocales. Se trata de un arácnido de la familia Hexathelidae, que alcanza considerable tamaño (hasta $35 \mathrm{~mm}$, excluidas las patas). Aparece en un puñado de localidades del suroeste peninsular: sur de Badajoz, Huelva, Córdoba, Sevilla, Cádiz, Jaén, Granada y Málaga, además de una población en Ceuta. Esta especie está incluida en el Convenio de Berna (anejo II) y en la Directiva Hábitat (anejo IV) (Ferrández y Fernández DE CÉSPEDES, 2001). Otras especies de arañas amenazadas incluidas en el Libro Rojo de los Invertebrados de España (Verdú y Galante, 2006) son: Agelena lepida, de las estepas monegrinas, Argyroneta acuatica, solamente conocida de la Laguna de Bañolas, Parachtes deminutus, de las cumbres de Sierra Nevada, Donacosa merlini, del Coto de Doñana, Telema tenella, araña cavernícola sólo conocida de la Cova del Far (Gerona), Pachygnata bonneti, endemismo ibérico de las orillas fluviales de Ciudad Real, Córdoba y Huelva, y Oxyptila bejarana, sólo conocida de un castañar de Béjar. Entre las arañas españolas cabe mencionar también Latrodectus tredecimguttatus, o viuda negra, de peligrosa picadura. La fauna canaria incluye una destacada biodiversidad de arañas, algunos de cuyos géneros están muy diversificados: Dysdera (43), Oecobius (35), Pholcus (16), Spermophorides (22), entre paréntesis se indica el número de especies.

Igualmente interesante es el único solífugo español, Gluvia dorsalis. Los opiliones ofrecen una considerable diversidad en España, con unas 125 especies, y numerosos endemismos cavernícolas, entre otros Maiorerus randoi, catalogada como En peligro de extinción y que únicamente se encuentra en un tubo volcánico de Fuerteventura (OROMí, 2006). El citado Libro Rojo de los Invertebrados de España (Verdú y Galante, 2006) recoge un pseudoscorpión, Troglobisium racovitzai, habitante de diferentes cuevas del nordeste ibérico. Por la singularidad del caso, debemos mencionar también la presencia en España de un orden de arácnidos típicamente tropical, como es el de los esquizómidos, una de cuyas especies se descubrió hace unos años de un tubo lávico en Tenerife.

\section{Miriápodos}

Como mencionábamos antes, las cuatro clases de miriápodos están representadas en la península Ibérica (tabla 5), con alrededor de 250 especies conocidas, lo que probablemente sea una exigua cantidad en relación con la riqueza faunística real, según se puede inferir de los datos para Italia (Minelli, 1996). Los miriápodos ibéricos incluyen desde especies relativamente grandes, como los ciempiés Scutigera coleoptrata (Chilopoda, Scutigeromorpha), de largas y ágiles patas, y Scolopendra cingulata (Chilopoda, Scolpendromorpha), potencialmente peligroso para los seres humanos, hasta los diminutos paurópodos y sínfilos, miriápodos translúcidos habitantes del suelo. En Canarias cabe destacar la gran diversidad de especies del diplópodo Dolichoiulus, con 46 especies (Machado, 2002). 


\section{Insectos}

La fauna de insectos (sensu lato) de España no es fácil de evaluar; las más conservadoras estimaciones indican que en la península Ibérica debe haber poco más de 40.000 especies descritas, mientras que otros cálculos apuntan más bien hacia las 50.000; a ellas habría que añadir las especies canarias que no aparecen en la península (endémicas o no) y que podrían ser tres o cuatro mil. Como en otros casos, el nivel de conocimiento de la fauna de insectos de España es muy desigual, tanto desde el punto de vista taxonómico, como del biogeográfico, ya que algunos grupos difícilmente aportarán novedades relevantes en cuanto a nuevas adiciones a la lista de especies, como los ropalóceros (mariposas diurnas), mientras que otros son una fuente inagotable de noticias taxonómicas, como los colémbolos o determinadas familias de coleópteros o de lepidópteros; igualmente sucede con respecto al territorio, pues algunas regiones están relativamente bien prospectadas y conocidas, como la Comunidad de Madrid, mientras que otras ofrecen extensas lagunas de información biogeográfica, como Castilla-La Mancha, Extremadura o amplias zonas de Castilla y León o Andalucía. En la tabla 6 recogemos los datos disponible o las estimaciones respecto al número de especies de cada orden.

Debido a la enorme amplitud del grupo, es impensable recoger en la necesariamente limitada extensión de este capítulo siquiera una pincelada de cada uno de los órdenes de insectos, por lo que únicamente ofreceremos una breve reseña de algunas especies particularmente llamativas, singulares o amenazadas, sin ninguna otra pretensión.

En relación con los coleópteros, el Libro Rojo de los Invertebrados de España(Verdú y Galante, 2006) recoge tres especies En peligro crítico; se trata de los carábidos Dicrodontus alluaudi y Trechus detersus; el primero es un escarabajo endémico de Gran Canaria y el segundo de Fuerteventura Y Lanzarote; la tercera especie es Cionus canariensis, un gorgojo (Curculionidae) endémico de Gran Canaria. Otros coleópteros amenazados y catalogados como En peligro son: Apoduvalius naloni, carábido cavernícola de Muñera (Asturias), Calathus amplius, carábido endémico de Tenerife, Ildobates neboti, carábido cavernícola de Castellón, Otiorhynchus torressalai, curculiónido cavernícola, Athypna iberica, escarabajo de la familia Glaphyridae, endemismo ibérico sólo conocido de las sierras del sur de Salamanca, Oresigenus jaspei, escarabajo cavernícola de la familia Leiodidae, sólo conocido de los Picos de Europa, Meloe foveolatus y Mylabris uhagonii, dos meloideos muy raros, Amaladera longipennis y Paratriodonta alicantina, dos escarabajos de la familia Melolonthidae, sólo conocidos de Alicante. En el Catálogo Nacional de Especies Amenazadas (tabla 8) se recogen algunos coleópteros como Pimelia granulicollis, un tenebriónido endémico de Gran Canaria En Peligro de Extinción, Osmoderma eremita (Cetoniidae) muy raro de los Pirineos, Cucujus cinnaberinus (Cucujidae), sólo conocida de Monte Muniellos (Asturias) y Limoniscus violaceus (Elateridae), sólo conocida de Picos de Europa (Cantabria) y del valle de Goñi y Sierra de Andía (Navarra), ambas especies ligadas a la madera podrida en bos-

128 ques de haya; Buprestis splendens, escarabajo Buprestidae ligado a los pinos, sólo co- 
nocido en España en las provincias de Cádiz, Cuenca y Granada; Lucanus cervus, el conocido ciervo volante, asociado a los robledales maduros de la mitad septentrional de la península; Rosalia alpina, un cerambícido ligada a los hayedos con madera podrida, Carabus (Mesocarabus) riffensis es un endemismo norteafricano, sólo conocido a las afueras de la ciudad de Ceuta. La fauna canaria de coleópteros es altamente interesante, con 1248 endemismos y una considerable diversificación de algunos géneros, como Acalles (27), Attalus (51), Calathus (24), Cardiophorus (31), Hegeter (22), Laparocerus (66), Longitarsus (17), Nesotes (20), Oxypoda (16), Pachydema(16), Tarphius (30) y Trechus (16) (entre paréntesis el número de especies, según MACHADO, 2002).

Los dípteros probablemente sean uno de los órdenes con más especies presentes en España. Según CARLES-TOLRÁ (2002), en España se han catalogado 6433 especies, de las que 5800 son de la España peninsular, 559 de Baleares y 1146 de Canarias; para la península (incluye, claro, Portugal) la cifra es 6106; para la región ibero-balear, 6184; para Europa, 17440, y para la región Paleártica, 34699; sobre un total mundial de 132111. La mayor diversidad está en los Cyclorrhapha, dípteros más bien de tipo mosca, con más de tres mil especies; de Nematocera (mosquitos en sentido general) se conocen 1873 especies españolas. Entre las familias más diversas se encuentran, entre los nematóceros, los quironómidos, con cerca de 500 especies españolas; y entre los ciclorrafos, los sírfidos (con 355), los múscidos (276) y los parasitoides taquínidos (514). De algunas familias se conoce relativamente bien la fauna (Syrphidae, Muscidae, Calliphoridae, etc.), mientras que de la mayoría el conocimiento es muy escaso y fragmentario. Aún así en los últimos años se han ido teniendo en cuenta en la elaboración de listas rojas, de manera que en el Libro Rojo de los Invertebrados de España (Verdú y Galante, 2006) se incluyen tres especies amenazadas: Caliprobola speciosa, un sírfido asociado a bosques sólo conocido en España en una localidad leonesa y catalogado como En peligro; Rhyncomyia italica, un califórido asociado a medios dunares, sólo conocido de Cerdeña y de un par de localidades levantinas y catalogado como Vulnerable; y Mallota dusmeti, otro sírfido muy raro del centro de la península, cuyas larvas son saproxílicas, es decir, están asociadas a la madera podrida.

Los efemerópteros son insectos evolutivamente muy antiguos, ligados a los cursos de agua, cuya fauna ibérica es relativamente rica, ya que se conocen al menos 120 especies. Su vinculación a los ríos, dados sus hábitos larvarios, convierte a estas especies en vulnerables a causa del lamentable estado de nuestros cursos de agua. Esa es la razón por la que en el Libro Rojo de los Invertebrados de España (Verdú y Galante, 2006) se incluyen siete especies de efemerópteros, todas ellas con la etiqueta de $E n$ peligro: Caenis nachoi, Torleya nazarita, Rhithrogena monserrati, Rhithrogena thomasi, Habrophlebia antoninoi, Prosopistoma pennigerum y Siphlonurus ireneae.

Los himenópteros son un extenso orden de insectos muy populares, entre los que se incluyen las abejas, las avispas y las hormigas, pero que igualmente agrupa a una miríada de pequeñas especies parasitoides, cecidógenas (que producen agallas en las plantas) o de otros hábitos, poco conocidas. La fauna española es particular- 
mente rica, ya que se conocen cerca de 10.000 especies. El papel de los himenópteros en los ecosistemas es de capital importancia, ya que constituyen una buena fracción de los polinizadores y de los parasitoides controladores de las poblaciones de otros insectos (Viejo y Ornosa, 1997). En el Libro Rojo de los Invertebrados de España (Verdú y Galante, 2006) se recogen tres abejorros y dos hormigas En peligro: Bombus (Megabombus) reinigiellus (endemismo de Sierra Nevada), Mendacibombus (Mendacibombus) mendax (de Pirineos) y Psithyrus (Fernaldaepsithyrus) flavidus (Pirineos y CordiIlera Cantábrica), los tres de la familia Apidae, y Goniomma compressisquama (endemismo ibérico sólo conocido de El Ejido, Almería) y Rossomyrmex minuchae(endemismo de Sierra Nevada y Sierra de Gádor, Almería), que son las dos hormigas.

Los lepidópteros son quizá uno de los órdenes de insectos más populares, debido a que entre ellos están las mariposas; sin embargo el carácter llamativo y la opinión benévola que estos insectos inspiran, no se suele extender a todos los miembros del orden, la mayoría de los cuales son polillas o falenas de aspecto anodino, cuyas larvas (orugas) no suelen gozar de muy buena opinión entre el público. Constituyen un excelente bioindicador de condiciones ambientales, debido sobre todo a la marcada propensión de muchas especies a comer en la fase larvaria de una sola especie vegetal o a lo sumo de unas cuantas (estenofagia). La fauna ibérica de lepidópteros, aun siendo extensa, es más bien pobre en relación con la diversidad mundial, ya que apenas llega al 3\% de las especies conocidas, lo que cabe atribuirse a la inmensa biodiversidad de las áreas tropicales y ecuatoriales; sin embargo si realizamos la comparación con Europa, la fauna ibérica es una de las más ricas, y si añadimos la fauna canaria, encontramos un valor añadido en cuanto a número de endemismos. En el mundo se conocen 4 subórdenes, 41 superfamilias, 107 familias y unas 200.000 especies (dato que varía según las fuentes); en la península Ibérica, 2 subórdenes, 29 superfamilias, 78 familias y unas 4250 especies.

En la tabla 9 mostramos un resumen de la fauna ibérica de lepidópteros, y podemos apreciar que las familias que mayor número de especies incluyen son los noctuidos, los geométridos y los pirálidos; las llamadas mariposas diurnas (ropalóceros o Papilionoidea y Hesperioidea) son alrededor de 224 especies.

TABLA 9

Lista ordenada de familias de lepidópteros ibéricos, con expresión del número de especies conocidas en la Península y en el mundo

\begin{tabular}{|l|l|l|l|c|c|c|}
\hline \multicolumn{1}{|c|}{ Suborden } & \multirow{2}{*}{ Infraorden } & \multicolumn{1}{|c|}{ Superfamilia } & \multicolumn{1}{|c|}{ Familia } & Subfamilia & $\begin{array}{c}\text { N. esp. } \\
\text { mundo }\end{array}$ & $\begin{array}{c}\text { N. esp } \\
\text { Iberia }\end{array}$ \\
\hline Zeugloptera & & Micropterigoidea & Micropterigidae & & 120 & 10 \\
\hline Aglossata & & Agathiphagoidea & Agatipagidae & & 2 & 0 \\
\hline Heterobathmiina & & Heterobathmioidea & Heterobathmiidae & & 10 & 0 \\
\hline Glossata & Dacnonypha & Eriocranoidea & Eriocraniidae & & 30 & 2 \\
\hline
\end{tabular}


TABLA 9 (cont.)

Lista ordenada de familias de lepidópteros ibéricos, con expresión del número de especies conocidas en la Península y en el mundo

\begin{tabular}{|c|c|c|c|c|c|c|}
\hline Suborden & Infraorden & Superfamilia & Familia & Subfamilia & $\begin{array}{l}\text { N. esp. } \\
\text { mundo }\end{array}$ & $\begin{array}{l}\text { NN. esp } \\
\text { Iberia }\end{array}$ \\
\hline & Lophocoronina & Lophocoronoidea & Lophocoronoidae & & 3 & 0 \\
\hline & Neopseustina & Neopseustoidea & Neopseustidae & & 10 & 0 \\
\hline & Exoporia & Hepialoidea & Hepialidae & & 500 & 6 \\
\hline & Heteroneura & Incurvarioidea & Incurvariidae & & $>100$ & 6 \\
\hline & & & Heliozelidae & & 100 & 2 \\
\hline & & & Adelidae & & & 22 \\
\hline & & & Crinopterigidae & & $<10$ & 1 \\
\hline & & Nepticuloidea & Nepticulidae & & $>600$ & 70 \\
\hline & & & Opostegidae & & 100 & 6 \\
\hline & & Tischerioidea & Tischeriidae & & 65 & 5 \\
\hline & Ditrysia & Tineoidea & Tineidae & & $>3000$ & 80 \\
\hline & & & Psychidae & & 600 & 60 \\
\hline & & & Eriocottidae & & 70 & 3 \\
\hline & & Gracillarioidea & Gracillariidae & & $>1600$ & 80 \\
\hline & & & Bucculatricidae & & $<100$ & 8 \\
\hline & & & Douglasiidae & & 25 & 2 \\
\hline & & Yponomeutoidea & Yponomeutidae & & 800 & 60 \\
\hline & & & Ypsolophidae & & & 20 \\
\hline & & & Heliodinidae & & 55 & 1 \\
\hline & & & Lyonetidae & & 200 & 2 \\
\hline & & & Glyphipterigidae & & 1000 & 7 \\
\hline & & Gelechioidea & Gelechiidae & & $>4000$ & 300 \\
\hline & & & Oecophoridae & & 4000 & 130 \\
\hline & & & Depressariidae & & & 69 \\
\hline & & & Xyloryctidae & & & 1 \\
\hline & & & Coleophoridae & & 1000 & 220 \\
\hline & & & Batrachedridae & & & 3 \\
\hline & & & Elachistidae & & 300 & 60 \\
\hline & & & Ethmiidae & & & 11 \\
\hline & & & Agonexenidae & & & 7 \\
\hline & & & Blastobasidae & & $>300$ & 8 \\
\hline
\end{tabular}


TABLA 9 (cont.)

Lista ordenada de familias de lepidópteros ibéricos, con expresión del número de especies conocidas en la Península y en el mundo

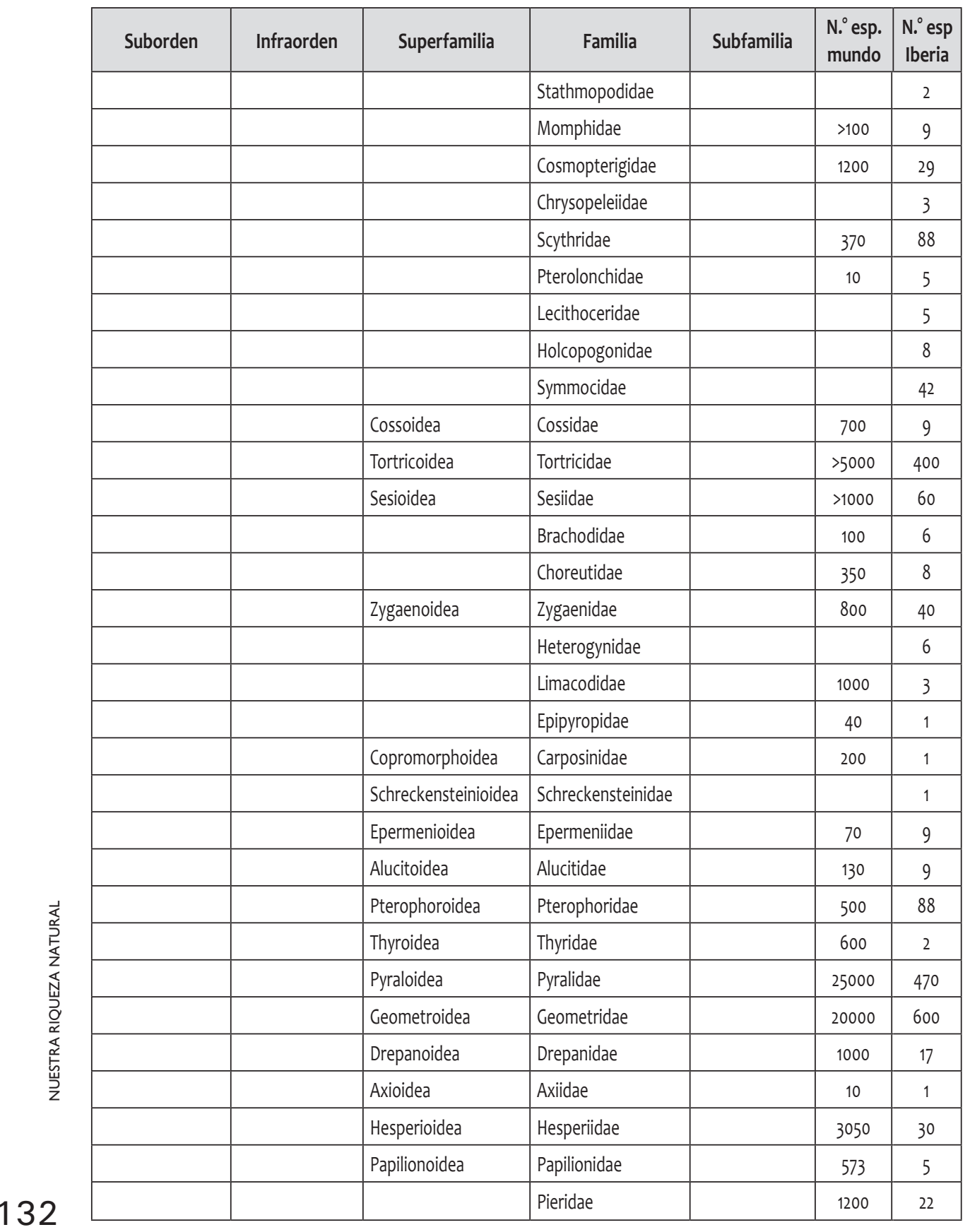




\section{TABLA 9 (cont.)}

Lista ordenada de familias de lepidópteros ibéricos, con expresión del número de especies conocidas en la Península y en el mundo

\begin{tabular}{|c|c|c|c|c|c|c|}
\hline Suborden & Infraorden & Superfamilia & Familia & Subfamilia & $\begin{array}{l}\text { N. esp. } \\
\text { mundo }\end{array}$ & $\begin{array}{l}\text { N. esp } \\
\text { lberia }\end{array}$ \\
\hline & & & & Pierinae & 700 & 16 \\
\hline & & & & Coliadinae & 400 & 5 \\
\hline & & & & Dismorphiinae & 100 & 1 \\
\hline & & & Nymphalidae & & 6000 & 94 \\
\hline & & & & Satyrinae & 1500 & 52 \\
\hline & & & & Charaxinae & $>300$ & 1 \\
\hline & & & & Nymphalinae & 3000 & 38 \\
\hline & & & & Danainae & 150 & 2 \\
\hline & & & & Libytheinae & 10 & 1 \\
\hline & & & Lycaenidae & & 4370 & 72 \\
\hline & & & & Lycaeninae & 3640 & 72 \\
\hline & & & Riodinidae & & 1000 & 1 \\
\hline & & Bombycoidea & Bombycidae & & 60 & 1 \\
\hline & & & Saturniidae & & 1300 & 6 \\
\hline & & & Endromidae & & 1 & 1 \\
\hline & & & Lemoniidae & & 20 & 2 \\
\hline & & & Lasiocampidae & & 2200 & 31 \\
\hline & & & Sphingidae & & 1050 & 24 \\
\hline & & Noctuoidea & Noctuidae & & 21000 & 704 \\
\hline & & & Notodontidae & & 2500 & 36 \\
\hline & & & Thaumetopoeidae & & 100 & 4 \\
\hline & & & Lymantriidae & & 2700 & 17 \\
\hline & & & Arctiidae & & 11000 & 62 \\
\hline TOTAL & & & & & 1188944 & 4243 \\
\hline
\end{tabular}

Fuente: Tomado de Scoble (1992) y Gómez de Aizpurua, González Granados y Viejo (1999)

En la tabla 10 detallamos el número de especies de las mariposas diurnas (ropalóceros o Papilionoidea y Hesperioidea) de la península Ibérica y de las islas Canarias, con expresión de los endemismos. 
TABLA 10

Lista ordenada de las familias de ropalóceros españoles, con expresión del número de especies por subfamilia (salvo Hesperiidae, Papilionidae $y$ Riodinidae).

Entre paréntesis se indica el número de especies endémicas

\begin{tabular}{|l|l|c|c|c|c|}
\hline \multicolumn{1}{|c|}{ Familia } & \multicolumn{1}{|c|}{ Subfamilia } & $\begin{array}{c}\mathbf{N}^{\circ} \text { especies } \\
\text { Mundo }\end{array}$ & $\begin{array}{c}\mathbf{N}^{\circ} \text { especies } \\
\text { Iberia }\end{array}$ & $\begin{array}{c}\mathbf{N}^{\circ} \text { especies } \\
\text { Canarias }\end{array}$ & $\begin{array}{c}\mathbf{N}^{\circ} \text { especies } \\
\text { España }\end{array}$ \\
\hline Hesperiidae & & 3050 & $30(0)$ & $1(0)$ & 30 \\
\hline Papilionidae & & 1200 & $22(0)$ & $8(2)$ & 25 \\
\hline Pieridae & Pierinae & 700 & $16(0)$ & $5(1)$ & 17 \\
\hline & Coliadinae & 400 & $5(0)$ & $3(1)$ & 7 \\
\hline & Dismorphiinae & 100 & $1(0)$ & 0 & 1 \\
\hline Nymphalidae & & 6000 & $94(6)$ & $12(2)$ & 98 \\
\hline & Satyrinae & 1500 & $52(6)$ & $3(2)$ & 54 \\
\hline & Charaxinae & $>300$ & $1(0)$ & 0 & 1 \\
\hline & Nymphalinae & 3000 & $38(0)$ & $7(0)$ & 40 \\
\hline & Danainae & 150 & $2(0)$ & $2(0)$ & 2 \\
\hline Lycaenidae & Libytheinae & 10 & $1(0)$ & 0 & 1 \\
\hline & & 4370 & $72(10)$ & $5(1)$ & 73 \\
\hline Riodinidae & Lycaeninae & 3640 & $72(10)$ & $5(1)$ & 73 \\
\hline TOTAL & & 1000 & $1(0)$ & 0 & 1 \\
\hline & & $>16000$ & $224(16)$ & $26(5)$ & 232 \\
\hline
\end{tabular}

Fuente: Tomado de Gómez de Aizpurúa, González Granados y Viejo, 1999.

Muchas son las especies de lepidópteros españolas que merecen destacarse pero, como en otros casos, la necesaria brevedad de este capítulo nos obliga a mencionar sólo unas cuantas. Entre las especies incluidas en el Catálogo Nacional de Especies Amenazadas (tabla 8) están:

- Polyommatus golgus. Este licénido es endémico de Sierra Nevada y está catalogado En peligro de extinción. En el Libro Rojo de los Invertebrados de España (Verdú y Galante, 2006) se incluye como En peligro.

- Maculinea nausithous. Licénido sólo conocido de siete localidades peninsulares, ligado a prados siempre verdes, cuyo ciclo biológico incluye una estrecha relación con hormigas (Myrmica). Está catalogado como Vulnerable. En el Libro Rojo de los Invertebrados de España (Verdú y Galante, 2006) también se cataloga como Vulnerable. 
- Eriogaster catax. Lasiocámpido muy raro catalogado como De interés especial, que sólo se ha encontrado en contadas localidades del tercio norte.

- Graellsia isabelae. Satúrnido catalogado como De interés especial, ligado a los pinares maduros de $P$. silvestris en diversas áreas del centro (Guadarrama, Sistema Ibérico), nordeste peninsular (Pirineos, Montseny, Beceite, etc.) y a $P$. nigra en Cazorla y Segura.

En el Libro Rojo de los Invertebrados de España (Verdú y Galante, 2006) se recogen 19 especies, siete de las cuales se consideran En peligro, entre ellas:

- Coscinia romei. Se trata de un árctido endémico de la península Ibérica, ligado a zonas áridas, sólo conocido actualmente en contadas localidades de la Serranía de Cuenca, Teruel y Madrid.

- Agriades zulichi. Licénido endémico de Sierra Nevada.

- Lycaena helle. Licénido ligado a praderas encharcadas que en España sólo se localiza en contados puntos de los Pirineos.

- Agrotis fortunata. Noctuido endémico de Tenerife.

- Eremopola (Eremochlaena) orana. Noctuido muy raro del litoral meridional.

- Eremopola (Eremopola) lenis. Noctuido mediterráneo, asociado a la banda esteparia costera.

Los odonatos (libélulas y caballitos del diablo) no son un orden particularmente diverso, ya que en el mundo sólo se conocen unas 6000 especies, y en la península Ibérica 78; sin embargo es uno de los grupos de insectos más populares, por su tamaño más bien grande y su aspecto llamativo; además son buenos bioindicadores de la calidad de las aguas a las que están ligadas por sus fases larvarias. Entre las especies españolas de odonatos merecen destacarse las siguientes:

- Ophiogomphus cecilia. Se trata de una libélula de la familia Gomphidae, incluida en el Catálogo Nacional de Especies Amenazadas, en la categoría En Peligro de Extinción, cuya presencia en la península Ibérica está confirmada en Portugal, y en España ofrece fuertes indicios.

- Lindenia tetraphylla. Es otro gónfido incluido en el Catálogo Nacional de Especies Amenazadas, en la categoría En Peligro de Extinción, sólo conocida por citas antiguas de Valencia. En el Libro Rojo de los Invertebrados de España (Verdú y Galante, 2006) se cataloga En peligro crítico. 
- Gomphus graslinii. Gónfido incluido en el Catálogo Nacional de Especies Amenazadas, en la categoría De interés especial, muy raro. En el Libro Rojo de los Invertebrados de España (Verdú y Galante, 2006) se cataloga En peligro.

- Macromia splendens. Es una libélula de la familia Cordulidae, considerada una reliquia del periodo glaciar, muy rara, con citas muy escasas en ríos de la mitad occidental, incluida en el Catálogo Nacional de Especies Amenazadas, en la categoría En Peligro de Extinción. En el Libro Rojo de los Invertebrados de Espa$\tilde{n} a$ (Verdú y Galante, 2006) se cataloga En peligro crítico.

- Oxygastra curtisii. Es un cordúlido, incluido en el Catálogo Nacional de Especies Amenazadas, en la categoría Sensible a la alteración de su hábitat, relativamente raro. En el Libro Rojo de los Invertebrados de España (Verdú y Galante, 2006) se cataloga En peligro.

- Leucorrhinia pectoralis. Libélula de la familia Libellulidae, sólo conocida en España en una localidad del Pirineo de Lérida, y catalogada en el Libro Rojo de los Invertebrados de España (Verdú y Galante, 2006) En peligro crítico.

- Coenagrion mercuriale. Libélula de la familia Coenagrionidae, incluida en el Catálogo Nacional de Especies Amenazadas, como De interés especial, dispersa por la península Ibérica, aunque rara.

Los ortópteros son los conocidos saltamontes y langostas, algunas de cuyas especies constituyen serias plagas agrícolas, pero que en España actualmente no constituyen una grave amenaza para los cultivos. En la península Ibérica se conocen poco más de trescientas especies, algunas incluidas en el Catálogo Nacional de Especies Amenazadas, como Baetica ustulata (Sensible a la alteración de su hábitat) y Acrostira euphorbiae, un panfágido endémico de La Palma (En Peligro de Extinción).

Los dictiópteros con frecuencia se escinden en Blattodea (cucarachas) y Mantodea (mantis o santateresas); en la península Ibérica se conocen unas 20 especies de cucarachas y unas 14 de mantis. Entre las primeras está Loboptera subterranea, un blatélido exclusivo de Tenerife, que vive en tubos volcánicos, y considerado En peligro En el Libro Rojo de los Invertebrados de España (Verdú y Galante, 2006); entre las segundas se incluye Apteromantis aptera, una mantis sin alas, endémica de la península Ibérica, considerada como De Interés Especial en el Catálogo Nacional de Especies Amenazadas.

\section{ECOSISTEMAS O ÁREAS DE ESPECIAL INTERÉS PARA LOS ARTRÓPODOS}

Como hemos visto, la riqueza faunística de España es elevada en la mayor parte de los grupos zoológicos, si bien el reparto de las especies no es uniforme a lo largo

136 del territorio nacional. Según de qué clase, orden o familia se trate es posible señalar 
ecosistemas o áreas naturales más ricos en especies; igualmente el concepto de riqueza no debe limitarse a la mera cifra del número, sino que debiera incluir la singularidad biogeográfica: endemismos, disyunciones, etc.

Entre otros muchos ecosistemas o áreas españolas de particular interés podemos mencionar los siguientes:

- Para los crustáceos marinos las áreas de mayor diversidad son las mismas que para el resto de la fauna marina. Puede consultarse el capítulo de José Templado, en este mismo volumen.

- Los tubos volcánicos de las islas Canarias albergan una fauna extremadamente singular, en el caso de especies tanto acuáticas (Jameos del Agua, en Lanzarote), como terrestres.

- En términos generales las islas Canarias constituyen un "minihotspot" o punto caliente de biodiversidad, con un elevado número de endemismos que, en términos relativos, alcanza las 7,1 especies $/ 100 \mathrm{~km}^{2}$, y que para los coleópteros es de 16,7 especies/100 km² (Machado, 2002).

- Los bosques son comunidades de gran interés faunístico, en especial aquéllos que conservan buena parte de su naturalidad. En estudios realizados sobre mariposas en la Comunidad de Madrid, los melojares y los quejigares son los bosques más ricos y diversos (Viejo y Templado, 1986; Romera et al., 2002).

- Los ecosistemas saproxílicos, es decir, los que se generan en torno a la madera podrida, son auténticas rarezas forestales. Speight (1989), en su trabajo para el Consejo de Europa, basándose en la presencia de especies indicadoras, elaboró un listado de bosques de importancia internacional para los organismos saproxílicos. En España cita los siguientes:

- JAÉN: bosques de Pinus y Quercus de la Sierra del Pozo en las Sierras de Cazorla-Segura.

- ALMERíA: bosques de Pinus y Quercus de la Dehesa de Alfaguara en la Sierra de María.

— CÁDIZ: bosques de pinsapo y quejigo de El Pinar en la Sierra de Grazalema.

- MÁLAGA: bosques de pinsapo y Quercus de la Sierra de las Nieves.

- MADRID: bosques de Fagus y Quercus del Hayedo de Montejo, en Montejo de la Sierra.

- NAVARRA: bosques de Picea y Fagus del Bosque de Irati. 
— LÉRIDA: bosques de Fagus y Abies del monte del Montseny.

- GERONA: bosques de Castanea de San Privat de Bas, entre los 600-800 m de altitud en Olot.

— TENERIFE: bosques de Laurus, llex y Prunus de El Pijaral.

- LA PALMA: bosques de Pinus canariensis del Pinar de Garafía.

- Las cumbres de los sistemas montañosos españoles albergan interesantísimas especies, muchas de ellas endémicas. Particular mención merece Sierra Nevada, donde se encuentran numerosas especies de insectos bien endémicas (por ejemplo los lepidópteros Agriades zullichi y Polyommatus golgus, o la hormiga Rossomyrmex minuchae), bien de sorprendente distribución disyunta.

- Los prados húmedos, donde sobreviven y prosperan especies relictas de épocas más húmedas y frías, como le sucede a la mariposa Maculinea nausithous.

- Los ecosistemas subterráneos ofrecen un gran interés en España, tanto en la península, como en las islas. Se trata de ambientes muy peculiares, en los que apenas existe producción (en términos ecológicos) y sus organismos son básicamente consumidores, al carecer de luz en la inmensa mayoría de los casos. Ya hemos comentado la importancia de los tubos volcánicos canarios, pero a ellos hay que añadir las cavernas peninsulares y baleares, repartidas en los siguientes distritos (Ortuño, 2002): cantábrico, vasco, pirenaico, catalán, levantino, bético, lusitánico, central y balear. En estas cavidades se encuentra una asombrosa diversidad de coleópteros (carábidos, estafilínidos, catópidos, colídidos, etc.), pero también de colémbolos, tisanuros, dipluros, y muchos otros insectos, además de quilópodos y diplópodos (particularmente milpiés o iúlidos), arácnidos como arañas, pseudoescorpiones, opiliones, palpígrados, escorpiones, entre otros, y crustáceos, tanto en las aguas subterráneas (cladóceros, copépodos, batineláceos, termosbenáceos), como en tierra (isópodos).

- Los ecosistemas de aguas continentales están especialmente amenazados en España, y acogen una destacada riqueza faunística, tanto en número de especies, como en singularidad biogeográfica. Entre los artrópodos ligados a las aguas continentales, se encuentran ácaros (hidracnélidos), efemerópteros, odonatos, hemípteros, plecópteros, tricópteros, coleópteros (Hydrophilidae, Dytiscidae, Gyrinidae, Haliplidae, Hygrobiidae, etc.), dípteros y otros muchos insectos; así como crustáceos: sincáridos, anfípodos, copépodos, decápodos, etc.

- El medio edáfico alberga también una destacada riqueza faunística, en gran medida dominada por artrópodos, muchos de los cuales tienen un importan- 
te papel bioindicador. Entre la fauna edáfica se hallan numerosos endemismos o especies singulares de colémbolos, coleópteros, dípteros, ácaros (sobre todo oribátidos), miriápodos, etc.

En lo que respecta a las mariposas (Lepidoptera, Papilionoidea y Hesperioidea), la fauna está mucho mejor estudiada que en los demás grupos de insectos (incluido el resto de lepidópteros) y es posible ofrecer mucha más información referida a la riqueza de especies en áreas concretas. En la tabla 11 mostramos el número de especies de cada una de las familias de Hesperioidea y Papilionoidea presentes en cada una de las 81 cuadrículas de España peninsular delimitadas por los meridianos (columnas) y paralelos (filas) con un grado de intervalo (datos de Martín y Gurrea, 1990, modificado por VIEJO 1999). Se puede observar que las cuadrículas que corresponden al Sistema Ibérico son las más ricas en especies (más de 160). Sin embargo, y por útil que sea este sistema de medir la riqueza, el número de especies no debiera ser el único criterio para seleccionar áreas de máximo interés. Así, desde el punto de vista de la riqueza, para la declaración de áreas de máximo interés se han seleccionado especies singulares, aplicando criterios tales como: Especies restringidas a Europa (189 especies), Especies recogidas en el Apéndice II del Convenio de Berna y/o la Directiva de Hábitats (23 especies) y Especies amenazadas según el Libro Rojo de las Mariposas Europeas o el de la UICN (71 especies). El resultado de cruzar esta información se expresa en la tabla 12, donde se muestran áreas concretas de especial interés para las mariposas.

TABLA 11 (cont.)

Número de especies de cada una de las familias de Hesperioidea y Papilionoidea presentes en cada una de las 81 cuadrículas de España peninsular delimitadas por los meridianos (columnas) y paralelos (filas) con un grado de intervalo

\begin{tabular}{|c|c|c|c|c|c|c|c|c|c|c|c|c|c|c|c|}
\hline & $\begin{array}{l}90^{\circ} \\
\mathrm{W}\end{array}$ & $\begin{array}{l}8 .^{\circ} \\
W\end{array}$ & $\begin{array}{l}70^{\circ} \\
\text { w }\end{array}$ & $\begin{array}{l}6 .^{\circ} \\
W\end{array}$ & $\begin{array}{l}5 .^{\circ} \\
W\end{array}$ & $\begin{array}{l}4^{\circ} \\
W\end{array}$ & $\begin{array}{l}30^{\circ} \\
\mathrm{W}\end{array}$ & $\begin{array}{l}20^{\circ} \\
W\end{array}$ & $\begin{array}{l}10^{\circ} \\
\mathrm{W}\end{array}$ & $\begin{array}{l}0 . \\
\text { W }\end{array}$ & $\begin{array}{c}0 . \\
E\end{array}$ & $\begin{array}{c}10^{\circ} \\
E\end{array}$ & $\begin{array}{c}20^{\circ} \\
E\end{array}$ & $\begin{array}{c}30^{\circ} \\
E\end{array}$ & Familia \\
\hline \multirow[t]{6}{*}{$43 .^{\circ} \mathrm{N}$} & 12 & 14 & 17 & 18 & 20 & 20 & 18 & 18 & 17 & & & & & & Hesperiidae \\
\hline & 2 & 2 & 2 & 3 & 3 & 3 & 3 & 3 & 3 & & & & & & Papilionidae \\
\hline & 12 & 12 & 12 & 13 & 14 & 14 & 14 & 13 & 13 & & & & & & Pieridae \\
\hline & 11 & 15 & 22 & 33 & 35 & 41 & 37 & 38 & 35 & & & & & & Lycaenidae \\
\hline & 33 & 40 & 46 & 61 & 62 & 61 & 57 & 57 & 60 & & & & & & Nymphalidae \\
\hline & 70 & 83 & 99 & 128 & 134 & 139 & 129 & 129 & 128 & & & & & & Total \\
\hline \multirow[t]{6}{*}{$42 .^{\circ} \mathrm{N}$} & 12 & 17 & 18 & 19 & 21 & 21 & 20 & 20 & 20 & 20 & 24 & 22 & 19 & 19 & Hesperiidae \\
\hline & 2 & 2 & 2 & 3 & 4 & 4 & 4 & 4 & 4 & 5 & 5 & 5 & 5 & 4 & Papilionidae \\
\hline & 12 & 12 & 12 & 13 & 15 & 17 & 15 & 15 & 16 & 18 & 19 & 17 & 18 & 15 & Pieridae \\
\hline & 12 & 16 & 27 & 34 & 36 & 46 & 43 & 42 & 43 & 49 & 50 & 50 & 50 & 37 & Lycaenidae \\
\hline & 34 & 44 & 55 & 64 & 67 & 68 & 64 & 66 & 70 & 76 & 80 & 77 & 72 & 57 & Nymphalidae \\
\hline & 72 & 91 & 114 & 133 & 143 & 156 & 146 & 147 & 153 & 168 & 178 & 171 & 164 & 132 & Total \\
\hline
\end{tabular}


TABLA 11 (cont.)

Número de especies de cada una de las familias de Hesperioidea y Papilionoidea presentes en cada una de las 81 cuadrículas de España peninsular delimitadas por los meridianos (columnas) y paralelos (filas) con un grado de intervalo

\begin{tabular}{|c|c|c|c|c|c|c|c|c|c|c|c|c|c|c|c|}
\hline & $\begin{array}{l}90^{\circ} \\
W\end{array}$ & $\begin{array}{l}8 .^{\circ} \\
W\end{array}$ & $\begin{array}{l}70^{\circ} \\
\text { W }\end{array}$ & $\begin{array}{l}6 .^{\circ} \\
\mathrm{w}\end{array}$ & $\begin{array}{l}50^{\circ} \\
\mathrm{W}\end{array}$ & $\begin{array}{l}4 .^{\circ} \\
\mathrm{W}\end{array}$ & $\begin{array}{l}30^{\circ} \\
\mathrm{W}\end{array}$ & $\begin{array}{l}2{ }^{\circ} \\
W\end{array}$ & $\begin{array}{l}10^{\circ} \\
\mathrm{W}\end{array}$ & $\begin{array}{l}0 . \\
\text { w }\end{array}$ & $\begin{array}{c}0 . \\
E\end{array}$ & $\begin{array}{l}10^{\circ} \\
E\end{array}$ & $\begin{array}{l}2 .^{\circ} \\
E\end{array}$ & $\begin{array}{l}30^{\circ} \\
\mathrm{E}\end{array}$ & Familia \\
\hline \multirow[t]{6}{*}{$41 .^{\circ} \mathrm{N}$} & & 17 & 18 & 18 & 18 & 19 & 19 & 19 & 20 & 20 & 22 & 22 & 22 & 20 & Hesperiidae \\
\hline & & 3 & 3 & 3 & 3 & 3 & 4 & 4 & 4 & 3 & 3 & 3 & 5 & 3 & Papilionidae \\
\hline & & 13 & 13 & 13 & 15 & 16 & 15 & 14 & 14 & 14 & 15 & 16 & 17 & 15 & Pieridae \\
\hline & & 23 & 33 & 30 & 20 & 23 & 32 & 36 & 29 & 31 & 41 & 47 & 51 & 38 & Lycaenidae \\
\hline & & 51 & 54 & 48 & 44 & 45 & 54 & 52 & 52 & 52 & 60 & 66 & 70 & 54 & Nymphalidae \\
\hline & & 107 & 121 & 112 & 100 & 106 & 124 & 125 & 119 & 120 & 141 & 154 & 165 & 130 & Total \\
\hline \multirow[t]{6}{*}{$40 .^{\circ} \mathrm{N}$} & & 13 & 16 & 17 & 19 & 19 & 20 & 21 & 20 & 20 & 20 & & & & Hesperiidae \\
\hline & & 3 & 3 & 3 & 3 & 4 & 4 & 3 & 4 & 4 & 3 & & & & Papilionidae \\
\hline & & 14 & 14 & 15 & 15 & 16 & 18 & 15 & 16 & 15 & 14 & & & & Pieridae \\
\hline & & 27 & 28 & 23 & 25 & 34 & 38 & 34 & 44 & 43 & 29 & & & & Lycaenidae \\
\hline & & 48 & 51 & 50 & 49 & 56 & 56 & 53 & 56 & 58 & 48 & & & & Nymphalidae \\
\hline & & 105 & 112 & 108 & 111 & 129 & 136 & 126 & 140 & 140 & 114 & & & & Total \\
\hline \multirow[t]{6}{*}{$39 .^{\circ} \mathrm{N}$} & 11 & 15 & 15 & 16 & 19 & 19 & 20 & 20 & 21 & 20 & & & & & Hesperiidae \\
\hline & 3 & 3 & 3 & 3 & 3 & 3 & 3 & 3 & 4 & 4 & & & & & Papilionidae \\
\hline & 14 & 15 & 15 & 15 & 15 & 15 & 16 & 16 & 15 & 15 & & & & & Pieridae \\
\hline & 19 & 24 & 24 & 19 & 21 & 23 & 23 & 29 & 40 & 32 & & & & & Lycaenidae \\
\hline & 33 & 41 & 42 & 38 & 39 & 41 & 44 & 49 & 54 & 54 & & & & & Nymphalidae \\
\hline & 80 & 98 & 99 & 91 & 97 & 101 & 106 & 117 & 134 & 125 & & & & & Total \\
\hline \multirow[t]{6}{*}{$38 .{ }^{\circ} \mathrm{N}$} & 12 & 12 & 11 & 13 & 19 & 19 & 19 & 19 & 20 & 16 & 15 & & & & Hesperiidae \\
\hline & 3 & 3 & 3 & 3 & 3 & 3 & 3 & 3 & 3 & 3 & 3 & & & & Papilionidae \\
\hline & 15 & 15 & 15 & 15 & 16 & 16 & 16 & 16 & 16 & 17 & 14 & & & & Pieridae \\
\hline & 21 & 21 & 17 & 18 & 20 & 22 & 25 & 25 & 27 & 28 & 21 & & & & Lycaenidae \\
\hline & 30 & 32 & 31 & 35 & 39 & 41 & 42 & 42 & 42 & 42 & 33 & & & & Nymphalidae \\
\hline & 81 & 83 & 77 & 84 & 97 & 101 & 105 & 105 & 108 & 106 & 86 & & & & Total \\
\hline \multirow[t]{6}{*}{$37^{\circ} \mathrm{N}$} & & 9 & 12 & 20 & 20 & 21 & 20 & 21 & 18 & 15 & & & & & Hesperiidae \\
\hline & & 3 & 3 & 3 & 3 & 3 & 4 & 4 & 4 & 3 & & & & & Papilionidae \\
\hline & & 13 & 13 & 16 & 17 & 17 & 18 & 17 & 18 & 15 & & & & & Pieridae \\
\hline & & 18 & 18 & 20 & 22 & 25 & 38 & 31 & 29 & 22 & & & & & Lycaenidae \\
\hline & & 29 & 30 & 40 & 40 & 41 & 44 & 45 & 41 & 35 & & & & & Nymphalidae \\
\hline & & 72 & 76 & 99 & 102 & 107 & 124 & 118 & 110 & 90 & & & & & Total \\
\hline \multirow[t]{6}{*}{$36 .^{\circ} \mathrm{N}$} & & & & 12 & 17 & 19 & 21 & 21 & & & & & & & Hesperiidae \\
\hline & & & & 3 & 3 & 3 & 3 & 4 & & & & & & & Papilionidae \\
\hline & & & & 15 & 17 & 18 & 18 & 17 & & & & & & & Pieridae \\
\hline & & & & 19 & 22 & 23 & 31 & 28 & & & & & & & Lycaenidae \\
\hline & & & & 35 & 38 & 41 & 43 & 44 & & & & & & & Nymphalidae \\
\hline & & & & 84 & 97 & 104 & 116 & 114 & & & & & & & Total \\
\hline
\end{tabular}

140 Fuente: Datos de Martín y Gurrea, 1990, modificado por Viejo, 1999. 
TABLA 12

Áreas de especial interés para las mariposas (Papilionoidea y Hesperioidea)

\begin{tabular}{|l|l|c|c|}
\hline \multicolumn{1}{|c|}{ Área } & \multicolumn{1}{c|}{ Paisaje } & Especies & Superficie (Ha.) \\
\hline Picos de Europa & Riscos, bosques y praderas & 6 & 64.700 \\
\hline Peña de Orduña & Bosques y praderas & 3 & 2 \\
\hline Sierra de Guara & Bosques y praderas & 5 & 47.500 \\
\hline Panticosa & Praderas & 3 & 350 \\
\hline El Cadí y La Molina & Bosques y praderas & 4 & 50.000 \\
\hline Montseny & Bosques y cultivos & 4 & 30.100 \\
\hline Sierra de Urbión & Bosques & 4 & 25.000 \\
\hline Sierra del Moncayo & Bosques y praderas & 5 & 30.000 \\
\hline Alto Valle del Lozoya & Praderas & 6 & 6 \\
\hline Sierra de Albarracín, Montes & Bosques y praderas & 6 & 70.000 \\
\hline Universales y Alto Tajo & Bosques y praderas & 5 & 90.000 \\
\hline Serranía de Cuenca & Bosques & 5 & 30.000 \\
\hline Sierra de Gúdar & $\begin{array}{l}\text { Bosques y vegetación de alta } \\
\text { montaña }\end{array}$ & Bosques y riscos & 86.200 \\
\hline Sierra Nevada & Sierra de María & & 7.500 \\
\hline
\end{tabular}

Fuente: Según Munguira et al. (2003).

\section{BIBLIOGRAFÍA}

Bolea, L., 2001. Austropotamobius pallipes, pp. 147-162. En Los invertebrados no insectos de la "Directiva Hábitat" en España, Ramos, M.A., Bragado, D. y Fernández, J., 2001, Organismo Autónomo Parques Nacionales, Serie técnica, Ministerio de Medio Ambiente, Madrid. 222 pp.

Carles-Tolrá, M. (coord.), 2002. Catálogo de los Diptera de España, Portugal y Andorra (Insecta). Monografías S.E.A. vol. 8, Zaragoza. 323 pp.

Ferrández, M.A., y Fernández de Céspedes, H., 2001. Macrothele calpeiana, pp. 133-145. En Los invertebrados no insectos de la "Directiva Hábitat" en España, Ramos, M.A., Bragado, D. y Fernández, J., 2001, Organismo Autónomo Parques Nacionales, Serie técnica, Ministerio de Medio Ambiente, Madrid. 222 pp.

Gómez de Aizpurua, C., González Granados, J., y Viejo, J.L., 1999. Las mariposas del Sur de la Comunidad de Madrid. Riada 6. Editorial Doce Calles. Aranjuez, 333 páginas.

Machado, A., 2002. La biodiversidad de las islas Canarias, pp. 89-99. En La Diversidad Biológica de España, Pineda, De Miguel, Casado y Montalvo (eds.), 2002. Prentice Hall, Madrid, 412 pp. 
Martín, J., y Gurrea, P. 1990. The peninsular effect in Iberian butterflies (Lepidoptera: Papilionoidea and Hesperioidea). J. Biogeogr. 17: 85-96.

MMARM, 2009. Ministerio de Medio Ambiente y Medio Rural y Marino. www.mmarn.es. Munguira, M.L., García-Barros, E., y Martín, J., 2003. Spain, pp. 531-554. En C.A.M. Van Saaway \& M.S. Warren, eds., 2003. Prime Butterfly Areas in Europe: Priority sites for conservation. National Reference Centre for Agriculture, Nature and Fisheries, Ministry of Agriculture, Nature Management and Fisheries, The Netherlands.

Oromí, P., 2006. Maiorerus randoi. Rambla, 1993, pp. 80. En Verdú y Galante (eds.). Libro Rojo de los Invertebrados de España. Dirección General para la Biodiversidad. Ministerio de Medio Ambiente. Madrid. 412 pp.

Ortuño, V.M., 2002. Estado de conocimiento de los artrópodos de España. pp. 209234. En La Diversidad Biológica de España, Pineda, De Miguel, Casado y Montalvo (eds.), 2002. Prentice Hall, Madrid, 412 pp.

Parker, S.P. (ed.), 1982. Synopsis and Classification of Living Organisms. McGraw-Hill Book Company. 2. ${ }^{\circ}$ volumen. Nueva York, $1232 \mathrm{pp}$.

Ramos, M.A., y Templado, J. 2002. Invertebrados no insectos. En: La naturaleza de España (Reyero, J.M. ed.). Ministerio de Medio Ambiente, Madrid, pp. 190-207.

Romera, L., Cifuentes, J., Viejo, J.L., y Fernández, J., 2002. Los geométridos de la Sierra de Guadarrama: estacionalidad y relación con las formaciones vegetales (Insecta: Lepidoptera, Geometridae). Bol. Asoc. Esp. Ent., 26 (1-2): 145-162.

Scoble, M.J., 1992. The lepidoptera: form, function and diversity. Oxford University Press, Oxford.

Speight, M.G.R. 1989. Les invertébrés saproxyliques et leur protection. Council of Europe.

Templado, J., Calvo, M., Garvía, M., Luque, A.A., Maldonado, M., y Moro, L., 2004 (eds.). Guía de los invertebrados y peces marinos protegidos por la legislación nacional e internacional. Naturaleza y Parques Nacionales, Serie Técnica, Ministerio de Medio Ambiente. Madrid. 263 pp.

Verdú, J.R. y Galante, E. (eds.), 2006. Libro Rojo de los Invertebrados de España. Dirección General para la Biodiversidad. Ministerio de Medio Ambiente. Madrid. 412 pp.

Viejo J.L., y Ornosa, C. 1997. "Los insectos polinizadores: Una perspectiva antropocéntrica”. Boletín de la Sociedad Entomológica Aragonesa, 20: 71-74.

Viejo, J.L., y Templado, J., 1986. “Los piéridos, satíridos y ninfálidos (Lep.) de la región de Madrid en relación con las formaciones vegetales". Graellsia, 42: 237265.

Viejo, J.L., 1999. Las mariposas de Peñalara y del Valle del Lozoya. Primeros Encuentros Científicos del Parque Natural de Peñalara y del Valle del Paular, pp. 163-171. Comunidad de Madrid. 